\title{
Perceptions of the South African 24-Hour Movement Guidelines for Birth to 5 Years: A Qualitative Study
}

\author{
Catherine E. Draper, Takana M. Silubonde, Gudani Mukoma, and Esther M.F. van Sluijs
}

\begin{abstract}
Background: South Africa launched 24-hour movement guidelines for birth to 5 years in 2018. Perceptions of these guidelines were assessed as part of the dissemination process with community-based organizations in 2019. Methods: Fifteen dissemination workshops were held with community-based organization representatives and a range of stakeholders. Discussions were held with workshop attendees $(n=281)$ to obtain qualitative feedback on the guidelines and workshop. Six follow-up focus groups $(n=28)$ were conducted to obtain additional feedback on the guidelines and their dissemination. Discussions and focus groups were thematically analyzed. Results: Participants recognized the importance of the guidelines for the health and development of young South African children. Participants' perceptions of the guidelines were consistently positive. The participants acknowledged the alignment of the guidelines with other South African programs and initiatives, and that they addressed gaps. Screen time and sleep were identified as the behaviors needing particular attention among young South African children. The negative impact of COVID19 on young children's movement behaviors was acknowledged, especially regarding screen time. Conclusion: These findings provide evidence of stakeholders' positive perceptions of the South African guidelines and support the dissemination and implementation of these guidelines for the promotion of early childhood health and development in South Africa.
\end{abstract}

Keywords: early childhood, sedentary behavior, screen time, sleep

The 24-hour approach to movement behaviors (physical activity, sedentary behavior, screen time, and sleep) during the early years has been adopted by a number of countries, such as Canada ${ }^{1}$ and Australia, ${ }^{2}$ as well as at the World Health Organization. ${ }^{3}$ These guidelines draw on evidence that optimal levels of these behaviors are beneficial for young children's health and development. ${ }^{1-3}$ This recent shift toward integrated guidelines for children's movement behaviors considers their natural integration across a 24-hour period, communicating a more cohesive message for parents, caregivers, teachers, and practitioners. The 24-hour approach considers young children's health and development in the context of how they move throughout a usual day (a combination of sleeping, sitting, standing, and different intensities of physical activity) and recognizes that the whole day matters. ${ }^{4}$ There is a growing body of research that evaluates adherence to 24-hour movement guidelines and emphasizes that the composition of these behaviors in a 24-hour period is important for health across the lifespan. ${ }^{5}$

(C) 2022 The Authors. Published by Human Kinetics, Inc. This is an Open Access article distributed under the terms of the Creative Commons Attribution 4.0 International License, CC BY 4.0, which permits unrestricted noncommercial and commercial use, distribution, and reproduction in any medium, provided the original work is properly cited, the new use includes a link to the license, and any changes are indicated. See http://creativecommons.org/licenses/by/4.0. This license does not cover any third-party material that may appear with permission in the article.

Draper, Silubonde, and Mukoma are with the SA MRC Developmental Pathways for Health Research Unit, School of Clinical Medicine, University of the Witwatersrand, Johannesburg, South Africa. van Sluijs is with the MRC Epidemiology Unit \& UKCRC Centre for Diet and Activity Research (CEDAR), School of Clinical Medicine, University of Cambridge, Cambridge, United Kingdom; and with the SA MRC Developmental Pathways for Health Research Unit, School of Clinical Medicine, University of the Witwatersrand, Johannesburg, South Africa. Draper (catherine.draper@wits.ac.za) is corresponding author.
South Africa was the first low- and middle-income country to develop 24-hour movement guidelines for birth to 5 years, which were launched in December $2018,{ }^{4}$ and to provide evidence-based recommendations for young children's physical activity, sedentary (sitting) behavior, screen time, and sleep. The process of developing these guidelines included a stakeholder consultation ${ }^{6}$ to ensure that they were contextually relevant and appropriate for South Africa. The guidelines are available as a text document (Figure 1) and an infographic that is available in all 11 of South Africa's official languages (English infographic shown as Figure 2). The South African guidelines align with the World Health Organization's global guidelines ${ }^{3}$ and guidelines from Australia $^{2}$ and Canada $^{1}$ (that have adopted the 24-h approach).

The dissemination of the South African guidelines was carried out in 2019 with community-based organizations (CBOs) working in early childhood development (ECD), and a program theory for this dissemination has been previously published. ${ }^{7}$ The community-based approach to dissemination was shown to be feasible and acceptable in the South African context and low-income settings, specifically. Evaluation of this dissemination found that CBOs (especially those that were particularly engaged in the dissemination process) were able to share these guidelines with the intended end users of these guidelines (including parents, caregivers, teachers, and practitioners) across a range of communities in South Africa. ${ }^{7}$ The original stakeholder consultation process highlighted a number of barriers to meeting the guidelines and competing priorities for those caring for young South African children but also indicated overall positive perceptions of the guidelines. ${ }^{6}$

Perceptions of guidelines can be an important indicator of their acceptability and hence the extent to which these guidelines will be disseminated and implemented by stakeholders and end users. Perceptions can encompass belief and attitudes and can draw on knowledge, all of which are considered to be determinants of behavior change ${ }^{8}$ and hence are applicable to the dissemination and implementation of guidelines. Qualitative methods are ideal for 


\section{SOUTH AFRICAN 24-HOUR MOVEMENT GUIDELINES FOR BIRTH TO FIVE YEARS}

An integration of physical activity, sitting behaviour, screen time and sleep

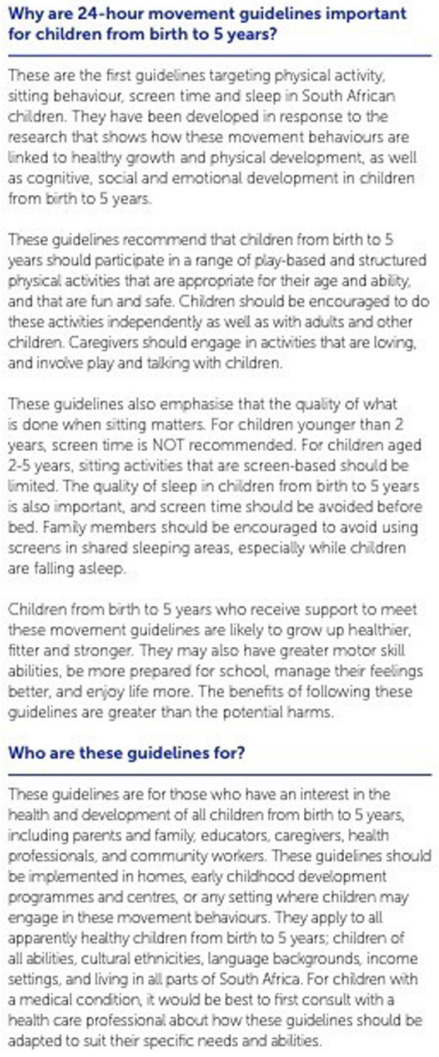

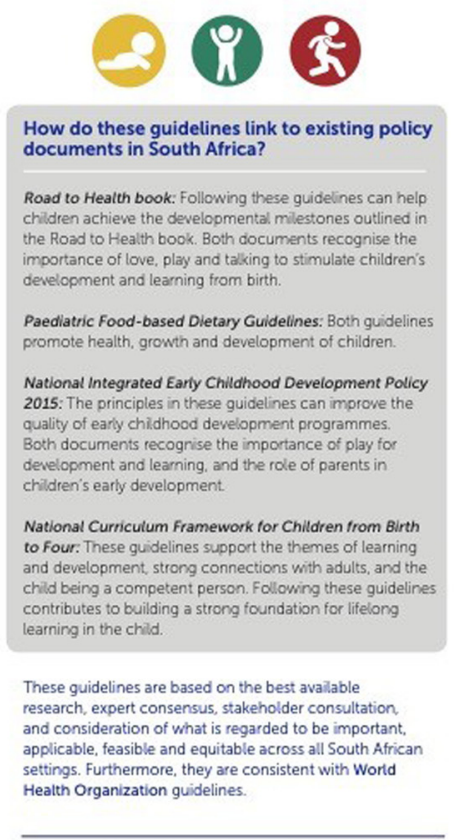

Further details on how to achieve these guidelines are available at www.laureus.co.za.

\section{A HEALTHY 24-HOUR DAY INCLUDES:}

\section{BABIES (BIRTH TO 1 YEAR OLD)}

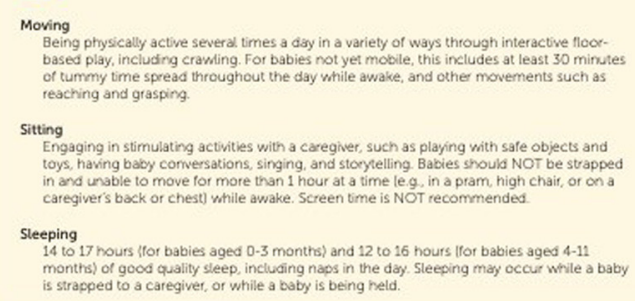

Screens include televisions, cell phones, and computers.
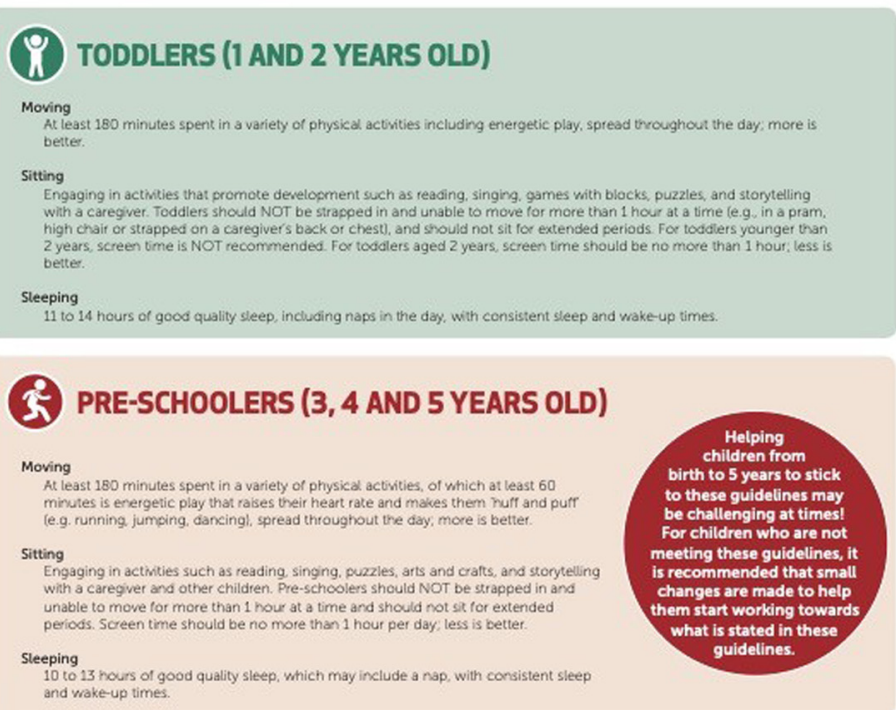
To further support children from birth to 5 years in their movement behaviours over a 24-hour day, encourage them to do
more energetic play, choose sge-appropriate, interactive sitting activities instead of sitting or lying in front of a screen, and

"Our children are the rock on which our future will be built our greatest asset as a nation." Nelson Mandela

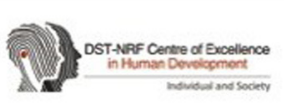

Figure 1 - South African 24-hour movement guidelines for birth to 5 years. ${ }^{4}$

exploring these perceptions in more depth, and qualitative studies have been conducted to explore stakeholders and end users' perceptions of early years movement guidelines in Canada, Australia, and the United Kingdom. ${ }^{9-11}$ While these studies identified overall positive views of these guidelines in their respective settings, challenges to implementing and achieving these guidelines were also highlighted, such as low awareness, competing priorities, quantifying behaviors, and not making parents feel guilty. ${ }^{9-11}$ While the evaluation of the dissemination of the South African guidelines picked up on many similar implementation challenges, ${ }^{7}$ the qualitative component of this evaluation provided an additional opportunity to obtain insight into $\mathrm{CBO}$ and end users' perceptions of the guidelines; these were not reported in the evaluation. Focus groups were previously shown to be an effective means to investigate collective views from different stakeholder groups (including potential end users) across a range of settings when the South African guidelines were being developed. ${ }^{6}$

These kinds of insights are essential for countries like South Africa, where movement behavior guidelines are novel and where awareness of guidelines is low. ${ }^{6}$ Understanding perceptions of guidelines can also be valuable in other countries that have developed or are developing similar guidelines. The aim of this paper is therefore to present CBO's and their end users' perceptions of the South African 24-hour movement guidelines for birth to 5 years.

\section{Methods}

\section{Project Phases}

This project had 4 phases, which took place from April 2019 to November 2020. These phases and the activities in each phase are described in detail elsewhere, ${ }^{7}$ but details relevant to the current analysis are briefly presented here. In phase 1, a CBO database was compiled, and dissemination activities were planned. In phase 2, 15 dissemination workshops with CBO representatives (which included some end users) were held in September 2019 in 7 of South Africa's 9 provinces, in both urban and rural settings. Quantitative feedback was obtained from attendees at the end of the workshop and has been reported elsewhere. ${ }^{7}$ Time was set aside at the end of the dissemination workshops to allow for a group discussion with attendees (facilitated by the workshop presenter) to collect additional qualitative feedback to supplement the quantitative feedback. Phase 3 involved the development of a marketing campaign. In phase 4, all dissemination 


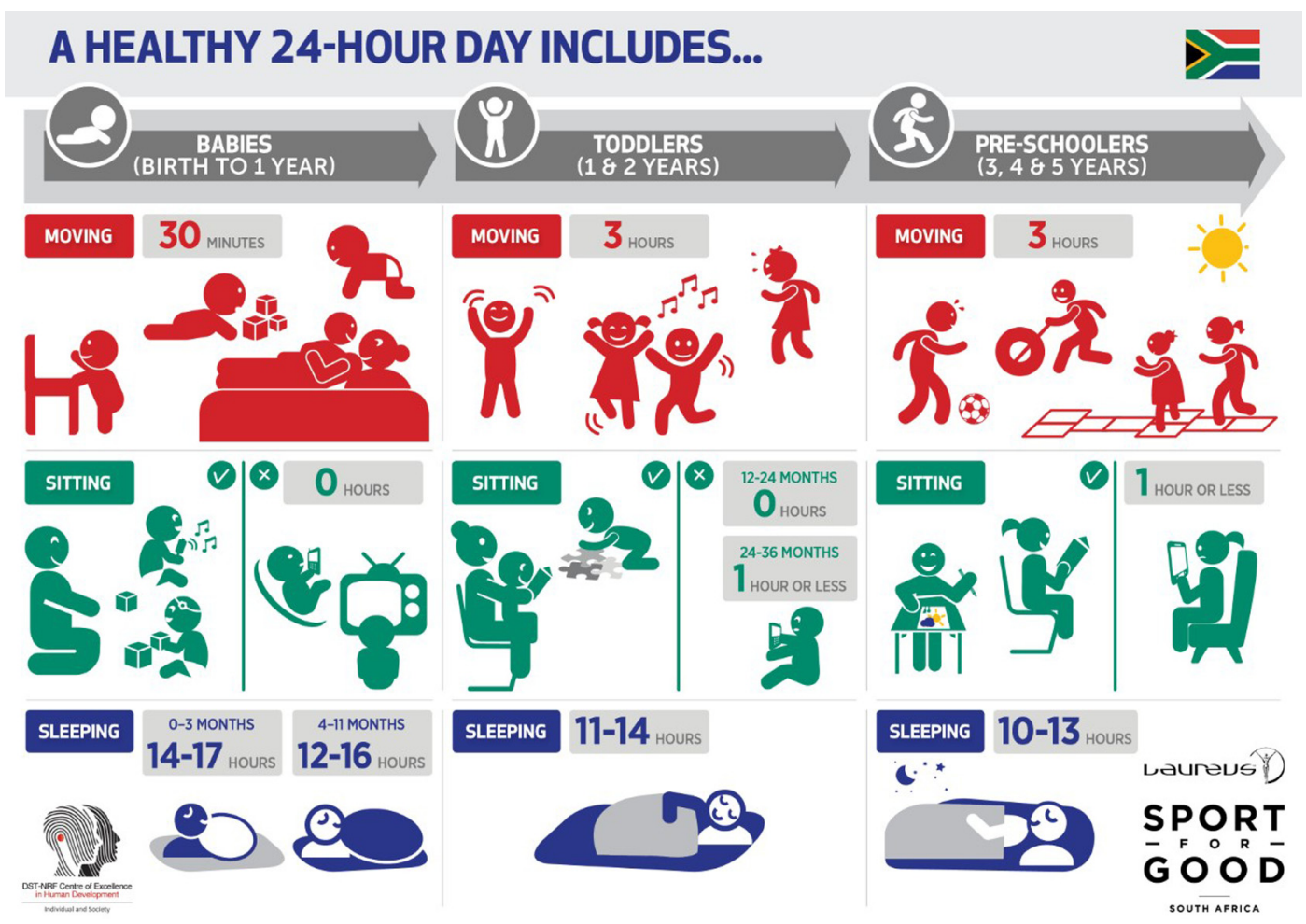

Figure 2 - South African 24-hour movement guidelines for birth to 5 years-English infographic. ${ }^{4}$

workshop attendees (for whom contact details were obtained with consent) were contacted to inquire about their willingness to participate in a follow-up focus group to obtain their feedback on the dissemination of the guidelines. The purpose of these followup focus groups was to evaluate the extent to which workshop attendees disseminated the guidelines to their staff and end users. This was viewed as a more feasible option compared with following up with all end users associated with the workshop attendees. $^{7}$

\section{Participants}

In phase 2, there was a total of 323 dissemination workshop attendees (range, $5-101 ; \mathrm{n}=281,87 \%$ provided quantitative and qualitative feedback). Participants included CBO representatives, local and provincial government representatives, ECD practitioners, academics, students, allied health professionals, and other community stakeholders. In phase 4,6 follow-up focus groups $(n=28)$ were conducted with CBO representatives (and some of their end users). One focus group was conducted in person (prior to the COVID-19 lockdown in March 2020), and the other focus groups were conducted virtually in July 2020 using a range of online platforms. Participants were from CBOs in KwaZulu-Natal (rural, $\mathrm{n}=9$ ), Gauteng (urban and periurban, $\mathrm{n}=16$ ), and the Western Cape (urban, $\mathrm{n}=3$ ).

\section{Data Collection}

At both the workshop discussions and follow-up focus groups, participants were able to share their perceptions about the guidelines. While the workshop discussions provided immediate qualitative feedback from workshop attendees regarding their perceptions of the guidelines, the follow-up focus groups provided a chance to explore their perceptions after the workshop attendees had the opportunity to disseminate and implement the guidelines. Based on the intended short-, medium- and long-term outcomes articulated in the program theory for the dissemination of the guidelines, guide questions were developed for the workshop discussions and follow-up focus groups. ${ }^{7}$ In addition to what has previously been reported, ${ }^{7}$ these questions addressed the importance and relevance of the guidelines and created an opportunity for participants to express their views about the importance of the early years, as well as any other perceptions about the guidelines.

\section{Data Analysis}

The workshop and focus group discussions were recorded, transcribed verbatim, and thematically analyzed using a largely deductive approach. ${ }^{12}$ The workshop discussion questions formed the basis of an initial thematic framework, and this was further developed to encompass the following main themes for the workshop discussions that are presented in this paper: (1) importance of the early years, (2) positive perceptions of the guidelines, and (3) importance of the guidelines. For the follow-up focus groups, the key theme relevant for this paper included feedback on the guidelines. The remaining themes from the workshops and focus groups are presented elsewhere. ${ }^{7}$ After the initial stage of familiarization with the data, codes were generated based on these themes. The next step involved searching for themes in the transcripts, and, once coded, sections of the text were summarized for each theme; illustrative quotes for each theme were extracted and are presented in Table 1.

Ethical approval for this research was obtained from the University of the Witwatersrand Human Research Ethics Committee (medical; ref: M190416). All participants gave written informed consent for their involvement in the study. 
Table 1 Selected Quotes for Themes

Theme
Importance of the early years

Positive perceptions of the guidelines

Importance of the guidelines

\section{Quote}

"I think movement is your foundation to all future learnings, and master your physical milestones from birth. Things like being able to get to a milestone whether it's rolling or sitting independently to actually getting up on your own. I think this blends in nicely with your core, with your foundation, it's like building a house, physical is your foundation. And then the sitting and the sleeping all leads to kind of you[sic] well-being and emotion so it links nicely as well. And then as you mention the cognitive development will happen anyway if these key things are done." (Johannesburg)

"We do know the developmental stages there, but to have it all on one paper is much easier to understand and maybe to explain to our colleagues and or[sic] parents. Maybe some don't understand the languages, but the picture is quite careful and easy to read as well." (Johannesburg)

"This isn't simple at all, but it is simplified in a way ... for some of us to understand. In the same way, where we have given examples of what we are able to do, we are always going to remember these examples. I think whoever designed this page did it very well." (Port Elizabeth)

"We have been talking about ideas for sitting, ideas for physical activity ... . So it is good to give an idea of what is actually expected like on the screen time. Also because this is a formal South African document, it adds weight for example to what our organisation is saying. It is nice to know that you have got other heavyweights behind you and for people to know that as well and it has just not been our thoughts." (Sweetwaters)

"You know according to my understanding with these guidelines is that they are not only meant for the classroom, they are meant for the child-minders and the practitioners which means they must take this advocacy to the parents, that when children are at home, they need to give them time to play. As you indicated at first, you said we are always watching TV. That is what parents do these days, so when our children come back from school for safety we keep them there. Now I understand that we need to advocate, take it to parents that they must understand ... . I think your guidelines are not meant for us as advisors, they go to a broader spectrum. They need to reach the parents, they need to reach us the grannies at home so that they at least give the children time to play so that they can develop, and that is what I learnt that is important." (Mbombela)

" ... to educate the rest of the family to understand and to adhere to why it is important. It's the mom that has to go against the family will she is the one who puts the TV down you know if the rest of the family is educated on why to conform with these guidelines I think it will be much easier to implement it." (Port Elizabeth)

"We have worked with ECD practitioners and we have been wanting ECD in Cape Town and I think this will help us very much because currently we are sitting with a challenge of children from 0-2 who are not stimulated on a daily basis and we sort of have a challenge because we don't know what do with them because from 2-5 we do have a curriculum but from 0-2 we just hitting a rock. So with this structure we have something to start working on, so I think that this has helped us quiet a lot, it has. It is something to start working on something, if I may put it that way." (Cape Town)

"Many ECD centres have the children at the table doing work that is not age appropriate either, that is one of the challenges. The time spent on physical activities is condensed on to half an hour. The rest of the time they are indoors. So that $[$ sic] something that has to change, because if we also going through a period of learn through play or play based learning it happens more with movement outside, that mind-set needs to change in ECD. We need to get children moving more or playing more." (Johannesburg)

"I think moving would also be one of the easiest thing[sic] because as ECD practitioners that's how children learn. They move through singing and dancing so you don't have to have the best equipment or the newest toys if you are creative you've got to think out the box and think what they are used to that it keeps them moving. So I think maybe parents wouldn't agree with that, that moving is not so easy but for us we know and understand how they enjoy moving so I think that as a teacher would be easy too." (Port Elizabeth)

"You see, also the sleeping time is very important. I knew that children should sleep, I knew that sleeping is a good thing but I didn't take it into that sense that I should do it properly. And even if I can do it as a routine that this time children will sleep and this time I will wake up the children. That will allow the children to develop well." (Mbombela)

"So I work with caregiver's mainly one on one and mainly in the low socioeconomic sectors and I think in the last year, I have noticed a big increase on kids using their parent's phone. In one of the areas there was free wi-fi that was just installed so it is going to be very useful to give the parents more guidelines because they don't realise the impact that more screen time does have. And with it becoming more and more easily accessible. Education around it needs to happen so it is going to be very useful in those areas as well." (Cape Town) "I don't think parents or practitioners are aware of the negative consequences so to get this out to them will be very helpful and important. All the negative consequences children have from watching too much screen time not developing multi skills, being creative to explore ... . There is so much, moods, you know it's a lot and all the kids on depression it's quite a lot and to see them and their parents as they play they grab the phone and straight away they are on it. I don't think they even have a conversation on 'how was your day?' So it's very helpful." (Port Elizabeth) 


\section{Table 1 (continued)}

\begin{tabular}{|c|c|}
\hline Theme & Quote \\
\hline $\begin{array}{l}\text { Feedback on guidelines (follow-up } \\
\text { focus groups) }\end{array}$ & $\begin{array}{l}\text { "At day care, now that the day centres are closed, children are staying at home and they are no longer playing or } \\
\text { doing their usual activities during the day. They are only eating, watching TV and sleeping. That is all they do } \\
\text { now. They don't go outside because their parents are afraid of, their parents are afraid of catching the disease." } \\
\text { (Gauteng, peri-urban 1) } \\
\text { "They were saying that they [parents] don't have much to do with their children now that they are in lockdown } \\
\text { and now that we don't see them as often and they don't have the resources they need to get their children moving } \\
\text { so they are allowing them to watch TV because there is literally nothing else to do. But I was telling they do } \\
\text { things like with their kids, play outside and play in the sand rather than watching TV and they said they were } \\
\text { because some even sent me pictures so I think it's great that we had these guidelines because we were able to } \\
\text { show them things they can do in order to get the children moving instead of watching TV." (KZN 1) } \\
\text { "What is happening with COVID it affects the children as much as it's affecting the adults; because as they are } \\
\text { looking at their parents miserable, financially there's nothing to eat in the house; it also affects the children } \\
\text { mentally." (Gauteng, urban) }\end{array}$ \\
\hline
\end{tabular}

Note. ECD = early childhood development

\section{Results}

\section{Qualitative Feedback After the Workshops}

Importance of the Early Years. Many attendees recognized the importance of developmental milestones and of providing a strong foundation in the early years to help prepare young children for school. This was not just in terms of academic skills but also centered around being able to function well in a classroom environment (eg, sit still, concentrate), being independent, and having social skills. Movement was recognized as an important part of this foundation, and some expressed that emotional and cognitive development build on this foundation.

Positive Perceptions of the Guidelines. Attendees' perceptions of the guidelines were consistently positive, and the guidelines were described as "helpful," "interesting," and "practical." It was recognized that the guidelines align with other policy documents and can be integrated into existing programs and initiatives targeting 0- to 5year-old children in South Africa. Opinions expressed about the guidelines were that they can help identify developmental delays in young children, particularly regarding motor skills, and that the activities presented in the guidelines can encourage bonding between parents and children and help parents get to know their children better. It was also acknowledged that the guidelines support healthy routines, which were deemed to be important.

Attendees felt that the pictures in the guidelines' infographic make it easy to understand the guidelines, including for those who have limited literacy skills. This is relevant in South Africa, given the country's educational challenges and the fact that many young children are cared for by a grandparent who may not have had access to educational opportunities. Attendees believed that this infographic is a good tool to use when working with parents, caregivers, and other colleagues. Terms used to describe the infographic included "very well put together," "fantastic as a visual," "well designed," and "pretty."

Importance of the Guidelines. At all workshops, attendees stressed the importance of the guidelines. The relevance of these guidelines was emphasized, particularly for ECD practitioners and parents, and attendees stated that these groups should be involved in the implementation of these guidelines. Attendees also mentioned the relevance of these guidelines for child-headed households and for grandparents looking after young children, and it was stressed by some that the whole family should be involved, not just the mothers of children.
The need for guidance on times was highlighted, especially for screen time and to help educate people about the importance of movement for achieving certain developmental milestones. Many attendees believed that this information is not necessarily known at a community level, and some described parents as "hungry for information." A number of participant groups mentioned that the guidelines helped fill a gap and that they are particularly important for the 0- to 2-year age group since less is known about what to do with children of this age, in terms of their stimulation and movement, both in ECD settings and at home with parents/caregivers.

Attendees acknowledged that it is important for young children to have "down time," in addition to movement; they were supportive of the activities in the guidelines that children could do in this time, such as reading. With regard to the physical activity component of the guidelines, many attendees felt that physical skills are an important part of development and that this component of the guidelines would be easy to implement and promote. Part of this was to do with the fact that toys are not needed for physical activity, but they can be homemade, or other items can be used to help children be active, such as tires. Also, attendees commented that some ECD practitioners appreciate that learning happens through movement; although, this was not always understood by parents. Attendees felt that many parents know their children need to move and that restricting movement is detrimental to their growth, but some parents needed these guidelines, if they believe their children are too active, and needed to be reminded of the importance of this activity. According to attendees, in some ECD centers, the guidelines would also be needed if children (in the preschool age group) are spending too much time indoors and have limited time to be active.

With regard to the sleep component of the guidelines, many attendees commented that bedtimes for young children are a challenge, for various reasons: watching television late at night with other family members (additionally exposing them to inappropriate content), screens being easily available, having to get up early (to get to work and school), and the difficulty of getting children to sleep. Attendees acknowledged the importance of sleep for children to be able function well at school (and preschool) and that routine around sleep is good, emphasizing, again, the importance of having parents on board to promote healthy sleep behaviors.

It was widely recognized by attendees that screen time would be the most difficult guideline to implement, particularly in homes because of the amount of screen time (especially television) that young children are exposed to-even as babies, which was described as common practice. In addition to this, many families live in homes with few rooms, and sometimes only one room, 
which also contributes to screen time exposure. Attendees also mentioned that many parents think their child is clever if they can use technology and that technology can seem like a better way to stimulate your child. Attendees maintained that most ECD practitioners and parents do not know that babies should not be exposed to screen time and that education in this area is desperately needed since most parents and practitioners also do not realize the negative consequences of too much screen time.

Attendees remarked that screens have become a priority for children, but they were vocal about the negative impact of screen time that they noticed. These negative impacts included the fact that screens do not encourage children to think for themselves or problem solve; everything is quick, and things are too convenient; reliance on screens detracts from learning; screen time lacks mental stimulation and limits creativity; screen time limits social interaction and communication; and screen time can lead to developmental delays, including language. One participant said she knew of a young child who only "speaks cartoon" as a result of all the time he spends on screens. Some attendees expressed concern that children in high-income settings were learning on screens and then also going home to screens.

\section{Follow-Up Focus Groups}

At the follow-up focus groups, participants' feedback about the guidelines continued to be positive, and the importance of the screen time guideline for young children was emphasized again. Participants affirmed that the guidelines aligned with their approach to promote ECD and support caregivers. Participants agreed that COVID-19 had had a negative impact on young children's movement behaviors, particularly since South Africa's lockdown restrictions meant people were only allowed outside for essentials. This made it especially difficult to follow the movement guidelines, mostly in terms of limiting screen time. Participants also mentioned a disruption to daily routines and sleep patterns during the COVID-19 pandemic and a negative impact on the mental health of children. However, they acknowledged that the guidelines were a helpful resource to suggest alternative behaviors.

\section{Discussion}

This paper reports on CBO and end users' qualitative perceptions of the South African 24-hour movement guidelines for birth to 5 years, as key stakeholders in these guidelines. The findings show that participants acknowledged the importance of the early years and were able to view these movement guidelines within their understanding of ECD. Overall, participants had positive perceptions of the guidelines, and there was general agreement about the importance of these guidelines for the health and development of young children in South Africa. These findings support the adoption of a 24-hour approach to movement behavior in the early years, and childhood more broadly. These findings also confirm that this approach contributes to a more cohesive message for parents, caregivers, teachers, and practitioners.

Furthermore, the positive perceptions expressed by participants echo the findings of the original stakeholder consultation for the development of the guidelines ${ }^{6}$ and also complement the findings reported regarding CBO and end users' positive perceptions of the dissemination workshops, which indicated the feasibility and acceptability of the workshops across a range of settings in South Africa. ${ }^{7}$ These findings align with the studies on stakeholders and end users' perceptions of movement guidelines in other high-income countries, which also found an overall positive view of the guidelines, acknowledging challenges to implementing and achieving these guidelines as well. ${ }^{9-11}$

These findings highlight screen time and sleep as the 2 movement behaviors that should receive further attention in young South African children. This is supported by other evidence in the preschool age group, particularly in low-income, urban South African settings. ${ }^{13-15}$ While there are constraints to changing these behaviors in low-income, urban households, the findings presented in this paper align with other research, which has found that caregivers of young children in these settings are generally receptive to attempting to implement these changes, particularly if the focus is on child health and development in a more holistic sensenot just obesity prevention. ${ }^{16-18}$

In terms of potential intervention strategies, CBOs already working with caregivers and practitioners (ECD and health related) to promote any aspect of young children's health and development should be encouraged to incorporate input on screen time and sleep, in order to address these as priority behaviors. Strategies can use the infographic as a visual aid but should not be limited to the mere provision of a printed resource without an explanation and the opportunity to ask questions to stimulate understanding. This input can be tailored to CBO's typical delivery strategies, such as oneon-one interactions (eg, peer mentors, community health workers, home visitors) or in a group setting (eg, parent support groups or training sessions). It would also be beneficial for them to provide information and generate discussion on how healthy levels of these behaviors are beneficial for young children's health and development, especially since awareness of the detrimental consequences of certain behaviors (eg, excessive screen time or screen time for babies) has been shown to be low. This type of information was shared in the dissemination workshops to help to understand the question of "why" behind the guidelines. The CBOs are typically familiar with the contextual realities of their end users and are able to share this information in a way that is relevant and appropriate to their context.

The wide acceptability of the guidelines' infographic and its availability in all 11 of South Africa's official languages make it an ideal resource for CBOs to use as a resource with their end users, as well as an accompaniment to resources already disseminated at scale to caregivers and stakeholders working with young children in South Africa. This infographic can also be easily distributed by other child health practitioners, including pediatricians, general practitioners, and allied health professionals, as well as community health workers. Future research could include the evaluation of child health practitioners' perceptions of these guidelines and their recommendations for dissemination and implementation.

A further recommendation from these findings is to promote the inclusion of these guidelines in other policy documents and initiatives in South Africa. The alignment of these guidelines with existing policy documents has been acknowledged in this study and by stakeholders ${ }^{6}$ and is specifically pointed out in the guideline preamble (see Figure 1). In particular, these guidelines can accompany the Road to Health booklet since both emphasize the connection between caregivers and children and the importance of love, play, and talk to stimulate young children's development. The Road to Health booklet is part of the child health campaign by the South African National Department of Health for children under the age of 5 years, ${ }^{19}$ and it aligns with the Nurturing Care Framework. ${ }^{20}$ It is intended that this booklet is given to all women receiving antenatal care in the health sector. 
While a strength of this research is that it adds to a growing body of South African research about movement behaviors in early childhood, there were some limitations of this study. First, having a workshop facilitator conducting the workshop evaluation might have hindered participants from providing honest feedback. However, an opportunity for providing this kind of feedback was given in the written evaluation. Another limitation, not uncommon in qualitative research, is that it is likely that those who voluntarily attended a workshop and/or follow-up focus group would be more inclined to be positive about the guidelines. Furthermore, the response to the followup focus groups was limited, and this is likely related to COVID-19 and the lockdown, which had a particularly negative impact on the ECD sector in South Africa. It is possible that those CBOs who responded to participate in the focus groups were also more inclined to have more positive perceptions. These factors may have contributed to the findings being predominantly positive, and it should not be assumed that all CBOs would share these positive views.

\section{Conclusion}

This study provides further evidence of stakeholders' positive perceptions of the South African 24-hour movement guidelines for birth to 5 years. This evidence supports the dissemination and implementation of these guidelines for the promotion of early childhood health and development across all settings in South Africa. This can set young children on their best trajectories for health and development and help to set a good foundation for health, education, and human capital outcomes later in life.

\section{Acknowledgments}

The authors thank all the participants for their involvement in the study and CBOs for their efforts to disseminate the guidelines. This study was funded by the Cambridge-Africa ALBORADA Research Fund, with supplementary funding from the International Society of Behavioral Nutrition and Physical Activity. The work of EMF van Sluijs was supported by the Medical Research Council (unit program number MC_UU_00006/5) and undertaken under the auspices of the Centre for Diet and Activity Research (CEDAR), a UKCRC Public Health Research Centre of Excellence. Funding from the British Heart Foundation, Cancer Research UK, Economic and Social Research Council, Medical Research Council, the National Institute for Health Research, and the Wellcome Trust, under the auspices of the UK Clinical Research Collaboration is acknowledged (087636/Z/08/Z; ES/G007462/1; MR/K023187/1).

\section{References}

1. Tremblay MS, Chaput JP, Adamo KB, et al. Canadian 24-hour movement guidelines for the early years (0-4 years): an integration of physical activity, sedentary behaviour, and sleep. BMC Public Health. 2017;17(suppl 5):874. doi:10.1186/s12889-017-4859-6

2. Okely AD, Ghersi D, Hesketh $\mathrm{KD}$, et al. A collaborative approach to adopting/adapting guidelines - The Australian 24-Hour Movement Guidelines for the early years (Birth to 5 years): an integration of physical activity, sedentary behavior, and sleep. BMC Public Health. 2017;17(suppl 5):869. doi:10.1186/s12889-017-4867-6

3. Willumsen J, Bull F. Development of WHO guidelines on physical activity, sedentary behavior, and sleep for children less than 5 years of age. J Phys Act Health. 2020;17(1):96-100. PubMed ID: 31877559 doi:10.1123/jpah.2019-0457
4. Draper CE, Tomaz SA, Biersteker L, et al. The South African 24-hour movement guidelines for birth to 5 years: an integration of physical activity, sitting behavior, screen time, and sleep. J Phys Act Health. 2020;17(1):109-119. PubMed ID: 31877557 doi:10.1123/jpah.20190187

5. Rollo S, Antsygina O, Tremblay MS. The whole day matters: understanding 24-hour movement guideline adherence and relationships with health indicators across the lifespan. J Sport Health Sci. 2020; 9(6):493-510. PubMed ID: 32711156 doi:10.1016/j.jshs.2020.07. 004

6. Tomaz SA, Okely AD, van Heerden A, Vilakazi K, Samuels M-L, Draper CE. The South African 24-hour movement guidelines for birth to 5 years: results from the stakeholder consultation. $J$ Phys Act Health. 2020;17(1):126-137. PubMed ID: 31877558 doi:10.1123/ jpah.2019-0188

7. Draper CE, Silubonde TM, Mukoma G, van Sluijs EMF. Evaluation of the dissemination of the South African 24-hour movement guidelines for birth to 5 years. Int J Environ Res Public Health. 2021; 18(6):3071. PubMed ID: 33802649 doi:10.3390/ijerph18063071

8. Michie S, Abraham C. Interventions to change health behaviours: evidence-based or evidence-inspired? Psychol Health. 2004; 19(1):29-49. doi:10.1080/0887044031000141199

9. Riazi N, Ramanathan S, O’Neill M, Tremblay MS, Faulkner G. Canadian 24-hour movement guidelines for the early years ( $0-4$ years): exploring the perceptions of stakeholders and end users regarding their acceptability, barriers to uptake, and dissemination. BMC Public Health. 2017;17(S5):841. doi:10.1186/s12889-017-4853-z

10. Stanley R, Jones R, Swann C, et al. Exploring stakeholders' perceptions of the acceptability, usability, and dissemination of the Australian 24-hour movement guidelines for the early years. J Phys Act Health. 2020;17(1):120-125. PubMed ID: 31357261 doi:10.1123/ jpah.2019-0069

11. Bentley GF, Jago R, Turner KM. Mothers' perceptions of the UK physical activity and sedentary behaviour guidelines for the early years (Start Active, Stay Active): a qualitative study. BMJ Open. 2015;5(9):e008383. PubMed ID: 26351186 doi:10.1136/bmjopen2015-008383

12. Braun V, Clarke V. Using thematic analysis in psychology. Qual Res Psychol. 2006;3(2):77-101. doi:10.1191/1478088706qp063oa

13. Tomaz SA, Hinkley T, Jones RA, et al. Screen time and sleep of rural and urban South African preschool children. Int J Environ Res Public Health. 2020;17(15):5449. doi:10.3390/ijerph17155449

14. Tomaz SA, Prioreschi A, Watson ED, et al. Body mass index, physical activity, sedentary behavior, sleep, and gross motor skill proficiency in preschool children from a low- to middle-income urban setting. J Phys Act Health. 2019;16(7):525-532. PubMed ID: 31154894 doi:10.1123/jpah.2018-0133

15. Rae DE, Tomaz SA, Jones RA, et al. Sleep and BMI in South African urban and rural, high and low-income preschool children. BMC Public Health. 2021;21(1):571. PubMed ID: 33757479 doi:10. 1186/s12889-021-10591-5

16. Klingberg S, van Sluijs EM, Draper CE. Parent perspectives on preschoolers' movement and dietary behaviours: a qualitative study in Soweto, South Africa. Public Health Nutr. 2021;24(12):36373647. PubMed ID: 33077021 doi:10.1017/S1368980020003730

17. Klingberg S, Sluijs EMF van, Draper CE. "The thing is, kids don't grow the same": parent perspectives on preschoolers' weight and size in Soweto, South Africa. PLoS One. 2020;15(4):e0231094. PubMed ID: 32251449 doi:10.1371/journal.pone.0231094

18. Draper CE, Howard SJ, Rochat TJ. Feasibility and acceptability of a home-based intervention to promote nurturing interactions and healthy behaviours in early childhood: the Amagugu Asakhula pilot 
study. Child Care Health Dev. 2019;45(6):823-831. PubMed ID: 31335976 doi:10.1111/cch.12714

19. Slemming W, Bamford L. The new Road to Health Booklet demands a paradigm shift. South Afr J Child Health. 2018;12(3):86-87. doi:10. 7196/SAJCH.2018.v12i3.1595
20. World Health Organization, United Nations Children's Fund, World Bank Group. Nurturing care for early childhood development: A framework for helping children survive and thrive to transform health and human potential. Geneva: World Health Organization; 2018. 